\title{
Evaluation certain environment factors on wool characteristics of Arabi sheep breeds
}

\author{
Nosratollah Taherpour, Mahnaz Salehi, Farhad Mirzaei ${ }^{*}$ \\ Animal Science Research Institute of Iran, Karaj, Iran; 'Corresponding Author: farmir2003203@yahoo.com
}

Received 27 September 2011; revised 31 November 2011; accepted 9 December 2011

\begin{abstract}
Evaluation and grading of wool based on sex and age can help to improve economic value of wool. This study was conducted to investigate the wool production and fleece characteristics of Arabi sheep in Khuzestan province The right mid-side wool samples were taken from 90 Arabi sheep ( 1 - 4 years; 16 male and 74 female) by hand shearing. The staple length of shoulder, flank and rump were $13.18 \pm 0.27,13.31 \pm 0.22$ and $14.27 \pm 0.25 \mathrm{~cm}$, respectively. The greasy fleece weight, wool wax, vegetable matter, yield percentage, fiber diameter and its coefficient variation measures were $1.72 \pm 0.06 \mathrm{Kg} ; 2.77 \% \pm$ $0.12 \% ; 0.54 \% \pm 0.07 \% ; 73.36 \% \pm 0.68 \% ; 30 \pm 0.41$ $\mu \mathrm{m} ; 30.23 \% \pm 0.3 \%$ respectively. Correspondingly, the medulated fibers, true wool fiber and Kemp fibers were $21.6 \% \pm 1.9 \%, 76.1 \% \pm 2.04 \%$ and $2.5 \% \pm 0.57 \%$ respectively. Age and sex had a significant influence on staple lengths. Fleece weight $(P<0.01)$ and wool wax were $(P<0.05)$ affected by sex. There was no significant interaction between age and sex groups for fiber characteristics, but it was important for staple between body location $(P<0.05)$. There were a low considerable kemp and CV of wool diameter percentage on Arabi sheep in comparison with the other Iranian native sheep. The wide variation in fleece weight $(0.8-3.9 \mathrm{~kg})$; mean staple lengths $(8.8-19.2 \mathrm{~cm})$; medulated and kemp $(0$ 84.04 and $0 \%-30.22 \%$ ); fiber diameter (24.9 $37.43 \mu \mathrm{m}$ ) suggest potential for improvement of economical traits.
\end{abstract}

Keywords: Wool; Fleece Characteristics; Arabi Sheep

\section{INTRODUCTION}

The sheep population in Khuzestan province is around 4 million heads. About 30\% of them are Arabi breed where are distributed in Iran-Iraq border such as: shadegan; dast-e abbas; sosangerd; bostan; ahwaz and khoramshahr. The Arabi breed characterised as white, cream, black and dark/bright brown colour horned rams and polled ewes. The flocks are grazed the pasture for 4 - 6 months. Barley, hay and residual of harvested crops were used for feeding during of the winter. Lambs birth weight is 3 - $4 \mathrm{~kg}$. Lambs are fed milk for about 4 months. Milk production yield is $150-550 \mathrm{~kg}$ that is used only for lamb growth. Lambs mortality is $5 \%-30 \%$. They were usually migrated about 40 - $50 \mathrm{~km}$ for winter-feeding. Wool production is considered as its second importance in Arabi sheep performance. Shearing is done once a year and it is performed by hand blades in early spring. Wool is distributed all parts of body, except legs. Wool is used for felt and other traditional related products [1].

The objective of the present study was to evaluate fiber characteristics of Arabi breed reared in Khuzestan province condition. Effect of some of the environmental factors on the characteristics of fibers was also determined.

\section{MATERIALS AND METHODS}

The project was carried out at Safiabad research station, Khuzestan province, in south-eastern of Iran, near Persian Gulf, a humid sub-tropical environment $\left(13^{\circ} \mathrm{N}\right.$ $23^{\circ} \mathrm{N}, 25^{\circ} \mathrm{E}-48^{\circ} \mathrm{E}$ ) with a mean annual rainfall of 317.5 $\mathrm{mm}$ and mean temperature of $23^{\circ} \mathrm{C}$ [1]. The sheep have been grazed on pasture in spring and summer but a complementary ration containing Alfa Alfa hay and wheat straw were fed in autumn and winter. Pregnant and growing stock were fed with of $60 \%$ barley to meet their necessary requirements, $15 \%$ Wheat bran, $12 \%$ Cottonseed meal, $10 \%$ beet sugar pulp, $2 \%$ bone meal and $1 \%$ salt to maintain body weight and declining pasture quality. All animals were drenched with anthelmentics to control internal parasites; anti-tick bathing was carried out on wool shearing time. From these herd 90 sheep (1 4 years; 16 male and 74 female), were selected. Fleece weight (FW) was measured by scale balance [2]. Wool samples of about $20 \mathrm{~g}$ were taken just before shearing 
from fleeces of each sheep. Side samples were taken at the right side of the sheep from an area anterior to the last rib and midway between the belly and top lines. Before shearing the staple length of shoulder (SLS), flank (SLF) and rump (SLR) were measured by ruler [3]. The collected samples transferred to wool laboratory of Animal Science Research Institute for fiber testing. The visual subjectively and benzol test were used to separate the true wool (TW), medullated fiber (MF) and kemp (KF) percentage, and dry weights of them were determined by weighing. Wool wax (WW) determined by soxtec, vegetable matter (VM) by pincer, yield $(\mathrm{Y})$ in 4 scouring bowls [4]. A sub sample was paralleled in fibro liner component of Almeter $100^{1}$ to determine the Simi rigid length Hauteur (HFL), Barbe (BFL) and coefficient of variation of fibre length items). However the sample was prepared for measurement wool diameter by FDA $200^{2}$. Each sample was compressed and fibers were cut at midstaple with a heavy-duty cross-section device to provide snippets $200-300 \mu \mathrm{m}$ in length. Over two thousand fibers from each sample were measured. Mean fibre diameter (MFD) and coefficient of variation of fibre diameter (CVFD) were obtained for each sample.

The following model was used for statistical analysis by general linear model (GLM) using SAS software package (SAS/STAT User's Guide, 1987).

$$
\gamma_{i k m}=\mu+\alpha_{i}+\beta_{k}+(\alpha \beta)_{i k}+\varepsilon_{j k m}
$$

where $\gamma_{i k m}$ is individual records on every of traits, $\alpha_{i}$ is the effect of $i^{\text {th }}$ sex, $\beta$ is the effect of $k^{\text {th }}$ age, $(\alpha \beta)_{i k}$ is the interaction between sex and age and $\varepsilon_{j k m}$ is the residual effects.

\section{RESULTS AND DISCUSSION}

The result showed the average fleece weight of Arabi sheep was $1.72 \mathrm{~kg}$ (Table 1), that is more than some Iranian sheep breeds [5,6] and less than the others [7-12]. However the fleece weight ranges between $0.8-3.9 \mathrm{~kg}$ indicated the genetically capacity of Arabi sheep for wool production [13].

Tables 2 and 3 showed the wool characteristics of Arabi sheep by sex (male and female) and age (1 - 4 years). The fleece weight of yearling female was 1.67, 1.58, $1.80,1.62$ and $2.72 \mathrm{~kg}$ respectively. Mean fleece weight was $1.72 \pm 0.06 \mathrm{~kg}$ with $30 \% \mathrm{CV}$ and the difference between ewes and rams was statistically significant $(\mathrm{P}<0.01)$, but there was slightly differences among ages. In Arabi breed generally the male are heavier than female

\footnotetext{
${ }^{1}$ Almeter Al100, Peyer Texlab System, developed in cojunction with Centexbel and International Wool Sectetariat I.W.S. Siegfried Peyer Ltd. Ch-8832 Wollerau, Switzerland.

${ }^{2}$ Peyer Texlab System, FDA 200 Derermination of Fiber Fineness Distribution, User's Manual, developed in cojunction with Centexbel and International Wool Sectetariat I.W.S. Siegfried Peyer Ltd. Ch-8832 Wollerau, Switzerland.
}

and produce higher greasy wool than female [1], but maybe it is not significant difference between body weights in different ages of studied sheep. The effects of sex and age on fleece weight were not in agreement with previous findings $[14,15]$.They reported that, in yearling Romney sheep as well as Awassi sheep, the males were significantly heavier than females, but females had higher wool than males, and there was no significant effect of sex on each wool characteristics. Age had a significant influence on body weight and greasy fleece weight, but males and females had similar output.

True wool percentage in this research was higher than Iranian sheep breeds such as; Baluchi, Shal, but less than Mehrabani, Sandjabi and some Awassi sheep in the Middle East [6,16-18]. The mean staple length of Arabi sheep during of one year growth was recorded $13.59 \mathrm{~cm}$, it is long and very suitable material for woven hand carpet [1]. Staple lengths indicated significant differences ( $P$ $<0.01$ ) in terms of age and sex. Rump staple length was longer than shoulder's and flank's.

There was significant difference between sex $(\mathrm{P}<0.01)$ for wool fat and Hauteur fiber length but there was not statistical differences in terms of age. Obtained low Kemp fiber percentage is less than of the other Iranian sheep breeds [19]. However, the large value for coefficient variation of wool diameter showed there is no uniformity in wool concentration of Arabi sheep. However in comparison with mean fiber diameter ,this breed had less than the carpet wool breeds and Iranian sheep breeds, but coefficient of variation of fiber diameter was bigger than Iranian carpet wool breeds [1]. Although wool production is the second priority for the Arabi sheep keepers after milk production [1], but ultimately, the results of this study showed a good capacity of studied breed versus the wool performances of the other Iranian sheep breeds, regarding to fleece weight, wool diameter and wool production performance qualitatively and quan- titatively [1,5-13,18,19] (Table 4).

\section{CONCLUSION}

The Arabi sheep, integral part of socio-economic setup for smallholders of Southern region of Iran is an important genetic resource of milk and wool production. Some desirable wool characteristics like wool diameter and kemp fiber percentage of Arabi sheep resulted in conclusion that this wool can be used pure or blend, for different woolen products with considerable value added. In these studies demonstrated that Arabi sheep has long wool with low percentage of kemp fiber (2.56\%) and mean fiber diameter $(30 \mu \mathrm{m})$ which was less than Awassi breed in other countries. These specifications are ideal for carpet wool, but the wide variation in fleece weight (0.8 - $3.9 \mathrm{~kg})$, fiber diameter (24.9 - $37.43 \mathrm{um})$ and other 
Table 1. Fixed effects on fleece weight and wool length of Arabi sheep breeds.

\begin{tabular}{|c|c|c|c|c|c|c|c|c|}
\hline \multirow{2}{*}{ Effects } & \multirow{2}{*}{ No } & \multicolumn{7}{|c|}{ Traits } \\
\hline & & FW (kg) & SLS (cm) & $\mathrm{SLF}(\mathrm{cm})$ & SLR (cm) & WW (\%) & VM (\%) & Y (\%) \\
\hline Sex & & $* *$ & $* *$ & $* *$ & $* *$ & $*$ & NS & NS \\
\hline Male & 16 & $2.5 \pm 0.1$ & $15.7 \pm 0.7$ & $14.7 \pm 0.6$ & $16.2 \pm 0.6$ & $4.2 \pm 0.3$ & $0.4 \pm 0.2$ & $72.0 \pm 1.9$ \\
\hline Female & 74 & $1.5 \pm 0.0$ & $2.5 \pm 0.5$ & $13.3 \pm 0.3$ & $13.9 \pm 0.3$ & $2.5 \pm 0.1$ & $0.6 \pm 0.2$ & $74.2 \pm 0.9$ \\
\hline Age & & NS & ${ }^{* *}$ & $* *$ & $* *$ & NS & NS & NS \\
\hline Yearling & 20 & $1.7 \pm 0.1$ & $15.7 \pm 0.5$ & $14.7 \pm 0.4$ & $16.4 \pm 0.5$ & $3.2 \pm 0.2$ & $0.8 \pm 0.2$ & $72.5 \pm 1.5$ \\
\hline 2 years & 18 & $1.7 \pm 0.1$ & $15.7 \pm 0.8$ & $15.2 \pm 0.7$ & $16.5 \pm 0.5$ & $3.2 \pm 0.4$ & $0.5 \pm 0.3$ & $74.1 \pm 2.4$ \\
\hline 3 years & 16 & $1.8 \pm 0.1$ & $14.1 \pm 0.6$ & $14.4 \pm 0.5$ & $15.3 \pm 0.2$ & $3.2 \pm 0.3$ & $0.3 \pm 0.2$ & $76.2 \pm 1.7$ \\
\hline 4 years & 36 & $1.7 \pm 0.0$ & $13.2 \pm 0.4$ & $12.9 \pm 0.4$ & $14.2 \pm 0.4$ & $3.3 \pm 0.2$ & $0.4 \pm 0.1$ & $72.7 \pm 1.5$ \\
\hline Sex \& Age & NS & NS & NS & NS & NS & NS & NS & NS \\
\hline
\end{tabular}

${ }^{*},{ }^{* *} \mathrm{P}<0.05 \& \mathrm{P}<0.01$ respectively; NS: Not Significant.

Table 2. Fixed effects on wool quality of Arabi sheep breeds.

\begin{tabular}{ccccccccc}
\hline \multirow{2}{*}{ Effects } & \multirow{2}{*}{ No } & \multicolumn{9}{c}{ Traits } \\
\cline { 3 - 8 } & & TW $(\%)$ & MF $(\%)$ & KF $(\%)$ & MFD $(u)$ & CVFD $(\%)$ & HFL $(\mathrm{mm})$ & BFL $(\mathrm{mm})$ \\
\hline Sex & & NS & NS & NS & NS & NS & $*$ & NS \\
Male & 16 & $76.8 \pm 6$ & $22.9 \pm 5.4$ & $0.3 \pm 2$ & $30 \pm 1$ & $29.4 \pm 1$ & $40.7 \pm 1.8$ & $72.2 \pm 3.9$ \\
Female & 74 & $78.9 \pm 3$ & $18.2 \pm 2.7$ & $2.8 \pm 1$ & $32 \pm 0$ & $29.6 \pm 0$ & $35.3 \pm 0.9$ & $62.1 \pm 1.9$ \\
Age & & NS & NS & NS & NS & NS & NS & NS \\
Yearling & 20 & $77.3 \pm 4$ & $21.9 \pm 4.3$ & $2.1 \pm 1$ & $28 \pm 0$ & $32.4 \pm 1$ & $36.7 \pm 1.4$ & $63.2 \pm 3$ \\
2 years & 18 & $77.8 \pm 7$ & $18.72 \pm 6.7$ & $3.6 \pm 2$ & $30 \pm 1$ & $29.7 \pm 1$ & $41.6 \pm 2.3$ & $70.4 \pm 4.8$ \\
3 years & 16 & $72.5 \pm 5$ & $24.67 \pm 4.8$ & $2.7 \pm 2$ & $31 \pm 1$ & $28.2 \pm 1$ & $39.3 \pm 1.6$ & $71.5 \pm 3.5$ \\
4 years & 36 & $75.4 \pm 4$ & $23.61 \pm 3.7$ & $0.8 \pm 1$ & $30 \pm 0$ & $29.53 \pm 0$ & $36.5 \pm 1.2$ & $63.8 \pm 2.7$ \\
Sex \& Age & & NS & NS & NS & NS & NS & NS & NS \\
\hline
\end{tabular}

${ }^{*} \mathrm{P}<0.05$; NS: Not Significant.

Table 3. Simple Statistics for Arabi wool performances.

\begin{tabular}{|c|c|c|c|c|}
\hline Traits & & Mean \pm SE & CV & Range \\
\hline Fleece Weight (kg) & & $1.72 \pm 0.06$ & 30 & $0.8-3.9$ \\
\hline \multirow{4}{*}{ Staple Lengths (cm) } & Shoulder & $13.18 \pm 0.27$ & 28.48 & $5.6-23$ \\
\hline & Flank & $13.31 \pm 0.22$ & 16.83 & $8-18$ \\
\hline & Rump & $14.27 \pm 0.25$ & 17.43 & $10-21$ \\
\hline & Mean & $13.59 \pm 0.23$ & 16.68 & $8.8-19.2$ \\
\hline Wool Wax (\%) & & $2.77 \pm 0.12$ & 43.52 & $0.64-7$ \\
\hline Vegetable Mater (\%) & & $0.54 \pm 0.07$ & 129.5 & $0-6$ \\
\hline Yield (\%) & & $73.36 \pm 0.68$ & 9.23 & $52.3-87.7$ \\
\hline \multirow{3}{*}{ Fleece Fiber Contents (\%) } & True wool & $76.9 \pm 2.04$ & 26.86 & $0-100$ \\
\hline & Medullated & $21.6 \pm 1.9$ & 88.12 & 0 - 84.04 \\
\hline & Kemp & $2.56 \pm 0.57$ & 221.3 & $0-30.22$ \\
\hline Mean Fiber Diameter (micron) & & $30.6 \pm 0.41$ & 13.73 & $24.9-37.43$ \\
\hline Coefficient of Variation of Fibre Diameter (\%) & & $30.23 \pm 0.3$ & 10.06 & $24.17-37.4$ \\
\hline \multirow{2}{*}{ Fiber Length (mm) } & Hauteur & $35.7 \pm 0.6$ & 17 & $25.8-59.1$ \\
\hline & Barbe & $61.74 \pm 1.29$ & 21 & $40.01-103.3$ \\
\hline \multirow{2}{*}{ Coefficient of Variation of Fiber Length (\%) } & Hauteur & $85.03 \pm 1.02$ & 12 & $59-120$ \\
\hline & Barbe & $54.03 \pm 0.51$ & 9.5 & $42-65$ \\
\hline
\end{tabular}


Table 4. Phenotypic correlations between the fleece traits.

\begin{tabular}{cccccccc}
\hline Character & SLS & SLF & SLR & MFD & HFL & BFL & TW \\
\hline SLF & $0.74^{* *}$ & - & & & & & \\
SLR & $0.73^{* *}$ & $0.8^{* *}$ & - & & & & \\
MFD & $0.26^{*}$ & 0.1 & 0.11 & - & & & \\
HFL & $0.31^{*}$ & $0.34^{* *}$ & $0.31^{*}$ & 0.3 & - & & \\
BFL & $0.39^{* *}$ & $0.45^{* *}$ & $0.4^{* *}$ & $0.35^{*}$ & $0.86^{* *}$ & - & \\
TW & -0.11 & -0.11 & -0.11 & -0.14 & $-0.28^{*}$ & $-0.33^{*}$ & - \\
MF & 0.13 & 0.14 & 0.18 & 0.13 & $0.26^{*}$ & $0.32^{*}$ & $0.97^{* *}$ \\
FW & $0.29^{*}$ & $0.27^{*}$ & $0.35^{*}$ & -0.01 & 0.02 & 0.07 & 0.06 \\
\hline
\end{tabular}

${ }^{*},{ }^{* *} \mathrm{P}<0.05 \& \mathrm{P}<0.01$.

traits suggest potential for improvement of economical traits.

\section{ACKNOWLEDGEMENTS}

This study was supported by the Higher Research Commission of Agricultural research, education and extension organization. Also the authors wish to thank the farm staff of Animal Science Research Institute of Iran (ASRI).

\section{REFERENCES}

[1] Taherpour, N. and Salehi, M. (2003) Evaluation on wool characteristics of Iranian sheep breeds 5-Arabi sheep breed. Animal Science Research Institute, Final Report, Ministry of Agriculture, Iran.

[2] Anonym (1982) Breaking strength of wool fiber bundles one IN. Gage length. American Society for Testing Materials (ASTM), Annual Book, Afred Suter Co., New York, D, 2130-610.

[3] Anonym (1982) Diameter of wool and other animal fibers by micro projection. American Society for Testing Materials (ASTM), Annual book, Afred Suter Co., New York, USA, D1294-79, 32, 295-302

[4] Yeastes, N.T.M. (1965) Modern aspects of animal production. Butterworts, London.

[5] Demiruren, A.S., Beheshti, R.D., Salimi, H., Saleh, B.A. and Djaffari, A. (1971) A comparison of the reproductive and productive capacities of sheep Kallekui, Kizil and Baluochi breeds in Iran. Technical report, No. 1, Animal Husbandry Research Institute.

[6] Makarechian, M., Farid, A. and Safidbakht, N. (1977) Wool production in some fat tailed Iranian sheep breeds. 1-Some quantities characteristics of Karakul, Mehraban, Naeini, Ghezel and Bakhtiari breeds. Iran Journal Agricultural Research, 5, 1-5.

[7] Salehi, M. and Taherpour, N. (1992) Evaluation on wool characteristics of Iranian sheep breeds 2-Sangsari sheep breed. Animal Science Research Institute, Final report,
Ministry of Agriculture, Iran.

[8] Salehi, M., M. Hejazi Kenary, M., Taherpour, N. and Monem, M. (1994) An evaluation of Baluchi wool performances in Abas-Abad Station and local Baluchi sheep breed in Mashhad area. Animal Science Research Institute, Final report, Ministry of Agriculture, Iran.

[9] Salehi, M., N. Taherpour, N. and Monem, M. (2002) Study on wool performance of Baluchi sheep in Esfehan, Yazd and Kerman provinces. Pajouhesh-va-Sazandegi. Journal, 15, 16-19.

[10] Salehi, M. and Taherpour, N. (1998) Evaluation on wool characteristics of Iranian sheep breeds 4-Shall sheep breed. Animal Science Research Institute, Final report. Ministry of Agriculture, Iran.

[11] Siah-kamari, G., Edris, M.A., Movassagh, H. and Taherpour, N. (1998) Estimation of genetic and phenotypic parameters and study of the effects of certain environmental and genetic factors on fleece characteristics in Sanjabi sheep. M.Sc Thesis. Azad University, Esfahan, Iran.

[12] Sohraby, S. (1937) Les races de moutons et laine de I’Iran. Thèse présentée à la Faculté des sciences de l'Université de Paris pour obtenir le titre de docteur de l’Université, par Sohrab Sohraby,... Les Races de mouton et la laine en Iran [Reliure inconnue].

[13] Taherpour, N., Nik-khah, A., Monem M. and Kashanian, N. (1998) Effect of different levels of elemental sulfur and urea-treated barley straw on wool characteristics of lambs. Iranian Journal Agricultural Science, 29, 1-6.

[14] M.J. Tabbaa, Al-Azzawi, W.A. and Campbell, D. (2001). Variation in fleece characteristics of Awassi sheep at different ages. Small Ruminant Research, 41, 95-100. doi:10.1016/S0921-4488(01)00203-6

[15] Wuliji, T., Dodds, K.G., Andrews, R.N. and Turner, P.R. (2011) Selection response to fleece weight, wool characteristics, and heritability estimated in yearling Romney sheep. Livestock Science, 135, 26-31. doi:10.1016/j.livsci.2010.06.003

[16] Taherpour, N. (1988) A review on the most important studies of wool characteristics of Iranian native sheep. Animal Science Research Institute, Ministry of Agriculture, Iran.

[17] Taherpour, N. and Salehi, M. (1988) Evaluation on wool characteristics of Iranian sheep breeds 1-Moghani sheep breed. Animal Science Research Institute, Final report, Ministry of Agriculture, Iran.

[18] Taherpour, N. and Salehi, M. (1993) Evaluation on wool characteristics of Iranian sheep breeds 3-Sandjabi sheep breed. Animal Science Research Institute, Final report. Ministry of Agriculture, Iran.

[19] Taherpour, N. and Salehi, M. (2003) Evaluation on wool characteristics of Zel and Dallagh sheep breeds. Animal Science Research Institute, Final report, Ministry of Agriculture, Iran. 